\title{
Health-related quality of life in healthy children and adolescents of HIV-infected parents in Alexandria, Egypt
}

\author{
Original Mona H. Ashry', Hany H. Ziady', Maha A. Hameed ${ }^{2}$, Fatma T. Mohammed ${ }^{2}$ \\ Article \\ ${ }^{1}$ Department of Public Health and Community Medicine, Faculty of Medicine, Alexandria \\ University \\ ${ }^{2}$ Hospital of Hepatology, Gastroenterology and Infectious Diseases, Alexandria, Egypt
}

\begin{abstract}
Background: Egypt as part of the Eastern Mediterranean region is facing a growing HIV epidemic. Developments in the National HIV Program are associated with an increase in survival of HIV-positive persons. This study aimed to assess health-related quality of life (HRQOL) of healthy children/adolescents of HIV-positive parents compared with healthy children/adolescents of healthy HIV-negative parents.

Participants and Methods: A cross-sectional comparative study was conducted. Healthy children aged 3-17 years old of all HIV-positive parents registered in the national HIV treatment center in Alexandria Fever Hospital during the year 2016 were enrolled $(n=33)$ and compared with a comparable group of children of healthy parents $(n=33)$. The HRQOL of studied groups was assessed by interviewing parents using Kinder Lebensqualität Fragebogen questionnaire revised parents' version.

Results: Among the HIV-positive persons, $54.5 \%$ of their children had poor to fair HRQOL compared with only $9.1 \%$ of children of healthy parent group. They had significantly lower HRQOL scores in ; the physical, mental, family, and friends domains $(\mathrm{P}<0.05)$. Adolescents of HIV-positive parents had significantly lower HRQOL score compared with children $(\mathrm{P}=0.028)$. Parents' education was the only independent predictor of daughter/son's HRQOL ( $\mathrm{b}=13.073, \mathrm{P}=0.014)$.

Conclusion: HIV-positive status of parents negatively affects the HRQOL of their children. Development of organized social and mental support services to families with HIV-affected member/s within the Egyptian National HIV program is highly recommended with specific focus on adolescents and children, especially those having lower educated parents.
\end{abstract}

Received: 29 October 2017, Accepted: 22 January 2018

Key Words: Adolescents, children, Egypt, health-related quality of life, HIV effect, HIV-positive parents.

Corresponding Author: Mona H. Ashry, MD, Department of Public Health and Community Medicine, Faculty of Medicine, Alexandria University, El Khartoum Square, Alexandria Postal code 21544, Tel.: +20 1003142505 , E-mail: drmonahamdy@gmail.com

Journal of the Egyptian Public Health Association, ISSN: 0013-2446, Vol. 92, No.4

\section{INTRODUCTION}

In spite of the low prevalence $(0.1 \%)$ of HIV infection in the Eastern Mediterranean region, the increasing numbers of newly infected persons put it to the top list of WHO regions with HIV epidemic worldwide [1]. The situation in Egypt is almost a reflection to the region situation where the estimated prevalence of HIV infections is $0.013 \%$ with a growing epidemic especially among injecting drug users as well as men who have sex with men [2,3]. With the developments in the national HIV program through provision of HIV testing and antiretroviral drugs, there is an increase in the number of persons living with HIV $[3,4]$.

HIV infection does not affect only the infected person, but its effect extends to the family as a whole. Children and adolescents living with HIV-positive family member are vulnerable to many psychological, physical, and social problems, irrespective of disclosure of HIV status. These problems arise from the challenges faced by those children and adolescents inside and outside home [5]. Affected parent may avoid interacting with his children for fear of transmitting HIV to him/her or catching infections from the child. The psychological trauma child and adolescent experience during exacerbations of parent's symptoms may result in fear, anxiety, depression, grief, and low self-esteem. Moreover, he/she may be responsible for providing care to his/her affected parent at that time. The child custody may be transferred to another family member in case of parent inability to cope with the disease, which results in family disruption, loss of parental care, and loss of income. These problems may be doubled in case of loss of one or both parents owing to HIV/AIDS or other associated causes [6-8].

Owing to the marked association of HIV transmission with sexual behaviors and injecting drug use, stigma and discriminations against HIV-positive individuals may result in social isolation of the infected person and his/her 
family $[9,10]$. Egypt is an Islamic Arabic country where religious beliefs and cultural norms reject homosexual behaviors, extramarital sexual relationships as well as all forms of drug abuse. This explains the very low (0.4\%) accepting attitudes toward people living with HIV/AIDS, as reported in the Egypt health issues survey 2015, and it reflects the extent of stigma associated with HIV/AIDS in the society [11].

With the growing epidemic of HIV in Egypt and the expected increase in the number of surviving HIV-positive individuals as a result of the developments of the national HIV program, there will be an increase in healthy children and adolescents who are part of HIV-affected families. In addition, most research works have focused on HIVinfected children, and to our knowledge, there is no published research addressing the health-related quality of life (HRQOL) among healthy children of HIV-infected parents in Egypt. This study aimed to assess the HRQOL in healthy children/adolescents of HIV-positive parents compared with healthy children/adolescents of healthy HIV-negative parents.

\section{PARTICIPANTS AND METHODS}

A comparative cross-sectional study was conducted among healthy children/adolescents of HIV-positive parents and healthy children/adolescents of healthy parents. The study was carried out in Alexandria Hepatology, Gastroenterology, and Infectious Diseases Hospital (AHGIDH)-formerly Fever Hospital. It is a specialized governmental hospital located in Alexandria Governorate. It is one of the national HIV program centers for HIV/AIDS detection, diagnosis, treatment, and antiretroviral drugs distribution for registered cases. It serves four Egyptian governorates.

\section{Target population}

All healthy children/adolescents of HIV-positive parents registered for receiving antiretroviral drugs from the national HIV program center in AHGIDH during the year 2016 and aged 3-17 years were targeted. Restriction to this age group was based on the age specified by the used Kinder Lebensqualität Fragebogen (KINDL) questionnaire for HRQOL assessment [12]. A comparable group of children/adolescents of HIV-negative healthy parents were enrolled from the community for comparison. The selection of comparison group parents was based on age, sex, education, and occupation comparability with HIVinfected parents. They were selected from faculty members and hospital visitors. Exclusion criteria included any child/ adolescent experiencing any chronic disease.

There were 813 HIV-positive registered cases in the center. Those who attended regularly for receiving treatment were 400 cases. Among them, there were 43 parents, and only 27 parents had healthy HIV-negative children aged 3-17 years. The remaining parents had either children less than three or more than 17 years old or their children were HIV positive.

The total number of the studied children/adolescents of the interviewed HIV-positive parents was 33, where interviews were carried out with either the mother or father. An equal number of children/adolescents of healthy parents was enrolled in the study through interviewing 32 parents comparable to the HIV positive group regarding age, sex, education, and occupation to eliminate the effect of social status difference on the quality of life of studied groups.

\section{Data collection}

All enrolled parents were interviewed to collect required data. HIV-infected parents were interviewed in the national HIV treatment center in AHGIDH whereas the comparison group parents were either interviewed in the community medicine department or in their place of recruitment. A structured interview questionnaire was designed by the investigators to collect data regarding child/adolescent and parent demographics. The HRQOL of studied healthy children/adolescents was assessed using the KINDL questionnaire revised parents' version [12]. The questionnaire is available in many languages. Data were collected using the Arabic format [12]. It has 24 Likert-scaled items to assess six dimensions, namely, 'physical well-being', 'emotional well-being', 'selfesteem', 'family', 'friends', and 'every day functioning (school or nursery/kindergarten)'. Based on data collection and analysis guidelines stated in KINDL questionnaire manual, each item in the questionnaire referred to the child/adolescent feeling during the past week - as assessed by his/her interviewed parent - is assessed on a five-point Likert scale (never $=1$, seldom $=2$, sometimes $=3$, often $=4$, all the time $=5$ ). Eleven of the 24 items were reverse coded. For each studied dimension, a total score was calculated and transformed to values between 0 and 100. Moreover, a total HRQOL score was calculated [13].

For assessing the reliability of the questionnaire Arabic format, it was tested on 15 children/adolescents, and the calculated Cronbach's $\alpha$ was 0.91 , which indicates good internal consistency.

\section{Ethical considerations}

An approval from Alexandria Faculty of Medicine Ethics Committee and the Egyptian Ministry of Health was obtained. The aim of the study was clarified to each participant before enrollment. Privacy and confidentiality were ensured all through the research work conduction.

\section{Data analysis}

Data were analyzed using the statistical package for social sciences, version 18 (SPSS, PASW; SPSS Inc., Chicago, Illinois, USA). Quantitative variables were presented as range, mean, and SD. Frequency and percentage were used to describe qualitative variables. Studied HRQOL dimensions as well as the total HRQOL 
scores were categorized into very poor (scored from 0 to $<25$ ), poor (scored from 25 to $<50$ ), fair (scored from 50 to $<75$ ), and good quality of life (from 75 to 100 ). Based on the WHO classification of children ( $<15$ years), the group aged 3 to less than 10 years in the studied sample is classified as 'children', and based on the WHO definition of adolescents (10-19 years), the group aged 10-17 years is classified as 'adolescents' [14].

\section{Statistical analysis}

Statistical tests of significance used for comparing studied groups included Student's t, $\chi 2$, Fisher's exact, and Monte Carlo tests. Multiple linear regression analysis was carried out to determine independent predictors of HRQOL score. Independent variables tested were child/ adolescent age, sex, lost parent, parents' disclosure of their status to daughters/sons, family disruption (parent death or divorce), and parent education (low, including illiterate up to basic education, and high, including secondary education and higher). All results were interpreted at 5\% level of significance.

\section{RESULTS}

Table 1 shows the sociodemographic characteristics of both groups of interviewed parents.

The mean age of studied children/adolescents of HIV-positive parents group was higher than the age of the health parents group $(10.1 \pm 3.9$ years compared with $8.9 \pm 4.2$ years $(\mathrm{P}=0.242)$. Moreover, slightly more than half $(57.6 \%)$ of them were females compared with $48.5 \%$ of healthy parents group $(\mathrm{P}=0.459$; Table 2$)$.

Both parents of every child/adolescent in the first group had HIV-positive status, where all interviewed female parents acquired infection from their husbands. In addition, less than half $(n=14,42.4 \%)$ of those children/adolescents lost one of their parents owing to either HIV/AIDS or other associated causes. Moreover, only three of the studied adolescents knew the HIV-positive status of their parents.

Table 3 shows the results of the studied HRQOL six dimensions as well as the overall HRQOL level among both study groups. Children and adolescents of HIV-positive parents had a statistically significant poorer HRQOL in four of the studied six dimensions, namely, physical health, mental health, family, and friends, compared with children of healthy parents group $(\mathrm{P} \leq 0.05)$. On the contrary, in spite of having a lower HRQOL score for both self-esteem and school dimensions among HIV-positive parent group compared with healthy parent group, these differences are not statistically significant.

The overall HRQOL of children of the HIV-positive parent group was significantly lower than the healthy parent group. Slightly more than half $(54.5 \%)$ of children/ adolescents of HIV-positive parents had poor to fair HRQOL compared with only less than a tenth $(9.1 \%)$ of children of the healthy parents group ( $\mathrm{P} \leq 0.05$; Table 3$)$.

On comparing the HRQOL between children and adolescents of HIV-positive parents, it was revealed that all studied children had fair to good HRQOL (69.2 and 30.8\%, respectively) whereas one-fifth $(20 \%)$ of adolescents had poor HRQOL $(\mathrm{P} \leq 0.05)$. There was no statistically significant association between child/adolescent sex and loss of one parent and HRQOL (Table 4).

Multiple linear regression analysis revealed that a significant model included parent's education, child age, lost parent, and daughter/son disclosure $(\mathrm{F}=2.99, \mathrm{P} \leq 0.05)$. The only significant independent predictor of children HRQOL was parent's education. Secondary and higher level of education was a predictor of better HRQOL among children (Relative Risk $(R R)=13.073, \mathrm{P} \leq 0.05$; Table 5). 
Table 1. Distribution of interviewed parents according to their sociodemographic characteristics, Alexandria, Egypt, 2016

\begin{tabular}{|c|c|c|c|}
\hline Sociodemographic characteristics & HIV positive parents $(n=27)[n(\%)]$ & Healthy parents $(n=32)[n(\%)]$ & Test of significance \\
\hline \multicolumn{4}{|l|}{ Age (years) } \\
\hline Minimum-maximum & $28-65$ & $28-48$ & Student's t-test \\
\hline Mean \pm SD & $38.7 \pm 8.5$ & $36.9 \pm 5.4$ & $\mathrm{t}=1.001 \mathrm{P}=0.32$ \\
\hline \multicolumn{4}{|l|}{ Sex } \\
\hline Male & $2(7.4)$ & $7(21.9)$ & Fisher's exact test $\mathrm{P}=0.16$ \\
\hline Female & $25(92.6)$ & $25(78.1)$ & \\
\hline \multicolumn{4}{|l|}{ Education } \\
\hline Illiterate & $10(37)$ & $7(21.9)$ & Monte Carlo test $\mathrm{P}=0.186$ \\
\hline Read and write & $7(26)$ & $17(53.1)$ & \\
\hline Secondary & $5(18.5)$ & $5(15.6)$ & \\
\hline University and higher & $5(18.5)$ & $3(9.4)$ & \\
\hline \multicolumn{4}{|l|}{ Working } \\
\hline No & $19(70.4)$ & $21(65.6)$ & Monte Carlo test $\mathrm{P}=0.674$ \\
\hline Professional & $4(14.8)$ & $3(9.4)$ & \\
\hline Semiprofessional & 0 & $1(3.1)$ & \\
\hline Skilled & $3(11.1)$ & $4(12.5)$ & \\
\hline Manual & $1(3.7)$ & $3(9.4)$ & \\
\hline
\end{tabular}

Table 2. Distribution of studied children/adolescents according to the HIV status of their parents and their age and sex

\begin{tabular}{lccc}
\hline Child/adolescent characteristics & $\begin{array}{c}\text { Children/adolescents of HIV- } \\
\text { positive parents }(\mathrm{n}=33)\end{array}$ & $\begin{array}{c}\text { Children/adolescents of } \\
\text { healthy parents }(\mathrm{n}=33)\end{array}$ & Test of significance \\
\hline Age (years) & $3-17$ & $4-17$ & Student's t-test $\mathrm{P}=0.242$ \\
Minimum-maximum & $10.1 \pm 3.9$ & $8.9 \pm 4.2$ & $\mathrm{t}=1.181$ \\
Mean \pm SD & & $17(51.5)$ & $\chi 2-$ Test $=0.547 \mathrm{P}=0.459$ \\
Sex [n (\%)] & $14(42.4)$ & $16(48.5)$ & \\
Male & $19(57.6)$ & \\
Female &
\end{tabular}


Table 3. Comparison of health-related quality of life of children/adolescents of HIV-positive parents and the comparison parent group

\begin{tabular}{|c|c|c|c|}
\hline Health-related quality of life dimensions & $\begin{array}{l}\text { Children/adolescents of HIV- } \\
\text { positive parents }(\mathrm{n}=33)[\mathrm{n}(\%)]\end{array}$ & $\begin{array}{l}\text { Children/adolescents of healthy } \\
\text { parents }(\mathrm{n}=33)[\mathrm{n}(\%)]\end{array}$ & Monte Carlo test \\
\hline \multicolumn{4}{|l|}{ Physical health } \\
\hline Very poor & $1(3)$ & 0 & \multirow[t]{6}{*}{$\mathrm{P}<0.001^{*}$} \\
\hline Poor & $4(12.1)$ & 0 & \\
\hline Fair & $10(30.4)$ & 0 & \\
\hline Good & $18(54.5)$ & $33(100)$ & \\
\hline Minimum-maximum & $18.75-100$ & $75-100$ & \\
\hline Mean \pm SD & $69.3 \pm 20.8$ & $85 \pm 4.4$ & \\
\hline \multicolumn{4}{|l|}{ Mental health } \\
\hline Poor & $7(21.2)$ & 0 & \multirow[t]{5}{*}{$\mathrm{P}<0.001 *$} \\
\hline Fair & $19(57.6)$ & 0 & \\
\hline Good & $7(21.2)$ & $33(100)$ & \\
\hline Minimum-maximum & $25-100$ & $75-100$ & \\
\hline Mean \pm SD & $61.6 \pm 17.9$ & $89.2 \pm 9.4$ & \\
\hline \multicolumn{4}{|l|}{ Self-esteem } \\
\hline Poor & $5(15.2)$ & 0 & \multirow[t]{5}{*}{$\mathrm{P}=0.067$} \\
\hline Fair & $6(18.2)$ & $5(15.2)$ & \\
\hline Good & $22(66.6)$ & $28(84.8)$ & \\
\hline Minimum-maximum & $25-100$ & $56.3-93.8$ & \\
\hline Mean \pm SD & $72.2 \pm 22.4$ & $83.7 \pm 11.5$ & \\
\hline \multicolumn{4}{|l|}{ Family } \\
\hline Very poor & $2(6.1)$ & 0 & \multirow[t]{6}{*}{$\mathrm{P}=0.004^{*}$} \\
\hline Poor & $4(12.1)$ & 0 & \\
\hline Fair & $10(30.3)$ & $4(12.1)$ & \\
\hline Good & $17(51.5)$ & $29(87.9)$ & \\
\hline Minimum-maximum & $0-100$ & $56.25-100$ & \\
\hline Mean \pm SD & $66.1 \pm 24.2$ & $82.8 \pm 10.8$ & \\
\hline \multicolumn{4}{|l|}{ Friends } \\
\hline Very poor & $1(3)$ & 0 & \multirow[t]{6}{*}{$\mathrm{P}<0.001^{*}$} \\
\hline Poor & $1(3)$ & 0 & \\
\hline Fair & $10(30.3)$ & 0 & \\
\hline Good & $21(63.7)$ & $33(100)$ & \\
\hline Minimum-maximum & $18.75-100$ & $87.5-100$ & \\
\hline Mean \pm SD & $75 \pm 18.2$ & $93.9 \pm 2.9$ & \\
\hline \multicolumn{4}{|l|}{ School } \\
\hline Very poor & $3(9.1)$ & $2(6.1)$ & \multirow[t]{6}{*}{$\mathrm{P}=0.777$} \\
\hline Poor & $3(9.1)$ & $1(3)$ & \\
\hline Fair & $9(27.3)$ & $9(27.3)$ & \\
\hline Good & $18(54.5)$ & $21(63.6)$ & \\
\hline Minimum-maximum & $0-100$ & $25-100$ & \\
\hline Mean \pm SD & $67.8 \pm 28.8$ & $76.1 \pm 22.8$ & \\
\hline \multicolumn{4}{|l|}{ Total HRQOL } \\
\hline Poor & $4(12.1)$ & 0 & \multirow[t]{5}{*}{$\mathrm{P}<0.001^{*}$} \\
\hline Fair & $14(42.4)$ & $3(9.1)$ & \\
\hline Good & $15(45.5)$ & $30(90.9)$ & \\
\hline Minimum-maximum & $29.1-94.8$ & $70.8-90.6$ & \\
\hline Mean \pm SD & $68.7 \pm 15.3$ & $85.7 \pm 6.4$ & \\
\hline $\begin{array}{l}\text { HRQOL, health-related quality of life. } \\
\text { "Statistically significant at } \mathrm{P} \leq 0.05 \text {. }\end{array}$ & & & \\
\hline
\end{tabular}


Table 4. Distribution of studied children/adolescents of HIV-positive parents according to their health-related quality of life and demographic characteristics

\begin{tabular}{|c|c|c|c|c|c|}
\hline \multicolumn{6}{|c|}{ HRQOL [n (\%)] } \\
\hline Demographic characteristics & Poor & Fair & Good & HRQOL score & Monte Carlo test \\
\hline \multicolumn{6}{|l|}{ Age period } \\
\hline Child ( $\mathrm{n}=13)$ & 0 & $9(69.2)$ & $4(30.8)$ & $58.3-78.170 .4 \pm 6.6$ & $\mathrm{P}=0.028 *$ \\
\hline Adolescent $(n=20)$ & $4(20)$ & $5(25)$ & $11(55)$ & $29.1-94.867 .6 \pm 19.2$ & \\
\hline \multicolumn{6}{|l|}{ Sex } \\
\hline Male $(n=14)$ & $2(14.3)$ & $5(35.7)$ & $7(50)$ & $38.5-94.869 .9 \pm 17.1$ & $\mathrm{P}=0.893$ \\
\hline Female $(n=19)$ & $2(10.5)$ & $9(47.4)$ & $8(42.1)$ & $29.1-89.667 .7 \pm 14.4$ & \\
\hline \multicolumn{6}{|l|}{ Loss of one parent } \\
\hline No $(n=19)$ & $1(5.3)$ & $11(57.9)$ & $7(36.8)$ & $43.8-85.467 .1 \pm 10.7$ & $\mathrm{P}=0.088$ \\
\hline Yes $(n=14)$ & $3(21.4)$ & $3(21.4)$ & $8(57.2)$ & $29.1-94.870 .8 \pm 20.4$ & \\
\hline
\end{tabular}

HRQOL, health-related quality of life.

*Statistically significant at $\mathrm{P} \leq 0.05$.

Table (5) Multiple linear regression analysis for predictors of HRQOL of children and adolescents of HIV positive parents

\begin{tabular}{|c|c|c|c|c|c|c|}
\hline \multirow{2}{*}{$\begin{array}{c}\text { Independent } \\
\text { variable }\end{array}$} & \multirow{2}{*}{ B } & \multirow{2}{*}{ Std. Error } & \multicolumn{2}{|c|}{ Confidence interval } & \multirow{2}{*}{$\mathrm{t}$} & \multirow{2}{*}{$\mathrm{P}$} \\
\hline & & & Upper limit & Lower limit & & \\
\hline Parent education & 13.073 & 4.879 & 2.955 & 23.192 & 2.679 & 0.014 \\
\hline Child age & -0.806 & 0.664 & -2.183 & 0.572 & -1.213 & 0.238 \\
\hline Lost parent & 2.682 & 4.750 & -7.169 & 12.532 & 0.565 & 0.578 \\
\hline Child disclosure & 15.517 & 8.234 & -1.559 & 32.594 & 1.884 & 0.073 \\
\hline
\end{tabular}

[Model F=2.99 $\mathrm{P}=0.041 \quad$ Constant $=70.026] \quad \mathrm{P}<0.001$

\section{DISCUSSION}

The results of the present study revealed that children and adolescents of HIV-positive parents had significantly lower levels of HRQOL compared with children of healthy parent group $(\mathrm{P} \leq 0.05)$, although most studied children/ adolescents were unaware of the HIV-positive status of their parents. This can be attributed to the effect of parental HIV on the family. The disease nature, namely, chronicity, infectivity, and associated stigma as well as the associated economic and social consequences of parental ill health can markedly affect children/adolescents' well-being $[5,15,16]$.
Having a chronic disease was an exclusion criterion during enrollment of studied groups of children and adolescents to avoid negative effects on their physical and mental well-being during assessment. Physical and mental well-being levels of children of HIV parents were significantly lower than healthy parent group. This was in agreement with the findings of a review by Islam et al. [15] who confirmed that children living in families with HIV experienced numerous physical and mental problems. It was also reported that the physical and mental wellbeing of children was inversely related to the physical 
functioning and symptoms of their HIV-positive mothers $[17,18]$. These findings reflect the challenges faced by children and adolescents of HIV-positive parents, including disruption of parental care owing to disease or even loss of care owing to parental death. Disruption or loss of parental care is usually associated with loss of income, increased poverty, and forcing children to take over the parenting role at home.

The social effects of parental HIV/AIDS and associated stigma as well as parental loss owing to the disease shadow the children's self-esteem and family and friend relations [15]. In the current study, in spite of unawareness of most studied children of HIV-positive status of their parents, they still can experience social prejudice and discrimination without understanding the underlying cause. This was reflected on their self-esteem and family and friend relations. Daughters/sons of parents with HIV had lower self-esteem levels compared with healthy parents' daughters/sons; however, the finding was statistically insignificant, which may be related to the small sample. Moreover, they had significantly lower family and friend relation levels compared with healthy parents' children.

The HRQOL of adolescents was markedly affected compared with the HRQOL of their siblings (i.e. the children). This may be related to their higher ability to recognize and feel the effects of their parents' ill health, loss of income, social discrimination, and social disruption. Moreover, during episodes of exacerbation of parent's ill health, or after parent's death, they usually take familial responsibilities and caring of younger siblings [15].

On the contrary, there was a statistically insignificant difference in HRQOL among children who lost one of their parents and those who did not. This was in contrary to what was reported in a systematic review by Islam et al. [15] who stated that loss of parents owing to HIV has a negative effect on children's experience of childhood period. This finding could be because the presence of both HIV positive parents may have a profound negative effect on their children's HRQOL. Although death of one parent may result in immediate marked stress on daughters/sons, but on the long term, there is a relative relief resulting from ending the stress associated with the HIV positive status of the lost parent.

However, multiple linear regression analysis revealed that the only predictor of daughters/sons HRQOL score was parents' educational level. Parents who had secondary education and higher is a predictor of higher HRQOL among their children $(R R=13.07)$. This finding may be explained by the higher social level associated with higher level of education and subsequent better care of children. It may also be related to better understanding of disease nature, modes of transmission, and importance of treatment compliance, which would be reflected on HIV-positive parents' quality of life and relation with their daughters/ sons.

\section{Limitations of the study}

Although the current study included healthy daughters/ sons of all HIV-positive parents registered in the study setting, the small sample size is considered the main study limitation. In addition, the stigma associated with HIV infection made it difficult to interview children/adolescents themselves.

\section{CONCLUSION AND RECOMMENDATIONS}

Children and adolescents of HIV-positive parents had lower HRQOL levels compared with their peers in the same age. There is a significant effect on children/ adolescents' physical, mental, and social well-being, which may be reflected on their adult life. Parents' higher levels of education play a role in relieving the negative effects of their HIV status on daughters/sons.

Development of organized social and mental support services to families with HIV-affected member/s within the Egyptian National HIV program is highly recommended, with more focus on families of low educational level. Moreover, planned services should focus on adolescents as well as children living in families with HIV-affected members.

\section{Conflicts of interest}

No conflict of interest to be declared.

\section{REFERENCES}

1. World Health Organization. Eastern Mediterranean Region EMR. Health topics, AIDS/HIV/STI. [cited 2017 Aug 3] Available at: http://www.emro.who.int/ health-topics/aids-hivsti/index.html.

2. World Health Organization. Eastern Mediterranean Region Office. Egypt Health Profile 2015. 2016: pp. 9-10. [cited 2017 Dec 13] Available at: http:// applications.emro.who.int/dsaf/EMROPUB_2016_ EN_19264.pdf.

3. National HIV Program Situation and Gap Analysis. National AIDS Program Egypt; 2015. [Accessed 2017 Dec 13] Available at: http://www.unaids.org/ sites/default/files/country/documents/EGY_narrative_ report_2015.pdf.

4. April MD, Wood R, Berkowitz BK, Paltiel AD, Anglaret X, Losina E, et al. The survival benefits of antiretroviral therapy in South Africa J Infect Dis 2014; 209:491-499.

5. H Bogart LM, Burton OC, Kennedy D, Ryan GW, Elijah J, Murphy DA, et al. How parenteral HIV affects children. Santa Monica, CA: RAND Corporation; 2009.

6. Murphy DA, Marelich WD, Herbeck DM. Impact of maternal HIV health: a 12-year study of children in the parents and children coping together project. J Adolesc Health. 2012; 51:313-318. 
7. Richter LM, Mofenson LM. Children born into families affected by HIV. AIDS 2014; 28:S241-S244.

8. Thurman TR, Kidman R, Nice J, Ikamari L. Family functioning and child behavioral problems in households affected by HIV and AIDS in Kenya. AIDS Behav 2015; 19:1408-1414.

9. Hasnain M. Cultural approach to HIV/AIDS harm reduction in Muslim countries. Harm Reduct J 2005; $2: 23$.

10. Gańczak M, Barss P, Alfaresib F, Almazroueic SH, Muraddadc A, Al-Maskari F. Break the silence: HIV/ AIDS knowledge, attitudes, and educational needs among Arab university students in United Arab Emirates. J Adolesc Health 2007; 40:572.e1-572.e8.

11. El-Zanaty and Associates. Egypt Health Issues Survey 2015. Egypt: Ministry of Health and Population; 2015. 51-64.

12. KINDL Questionnaire for Measuring Health Related Quality of Life in Children and Adolescents. Ulrike Ravens-Sieberer \& Monika Bullinger; 2000. [cited 2017 Dec 13] Available at: https://www.kindl.org/ english/language-versions/arabic/ .
13. KINDL Questionnaire for Measuring Health Related Quality of Life in Children and Adolescents Manual. Ulrike Ravens-Sieberer \& Monika Bullinger; 2000. [cited 2017 Dec 13] Available at: https://www.kindl. org/english/manual/ .

14. World Health Organization. Young peoples: a challenge for society. Geneva: WHO; 1986. [cited 2017 Dec 13] Available at: http://apps.who.int/iris/ bitstream/10665/41720/1/WHO_TRS_731.pdf.

15. Islam MS, Minichiello V, Scott J. Children living in HIV families: a review. J Child Adolesc Behav 2014; 2:1000170.

16. Xu T, Wu Z, Rou K, Duan S, Wang H. Quality of life of children living in HIV/AIDS-affected families in rural areas in Yunnan, China. AIDS Care 2010; 22:390-396.

17. Murphy DA, Greenwell L, Mouttapa M, Brecht ML, Schuster MA. Physical health of mothers with HIV/ AIDS and the mental health of their children. J Dev Behav Pediatr. 2006; 27:386-395.

18. Bauman LJ, Silver EJ, Draimin BH, Hudis J. Children of mothers with HIV/AIDS: unmet needs for mental health services. Pediatrics 2007; 120:e1141-e1147. 